\title{
Turismo e sustentabilidade ambiental na comunidade de Barra Grande, Cajueiro da Praia, Piauí (PI) ${ }^{1}$
}

\author{
Tourism and environmental sustainability in the community of Barra \\ Grande, Cajueiro da Praia, Piauí (PI)
}

\section{Turismo y sostenibilidad ambiental de la comunidad de Barra Grande, Cajueiro da Praia, Piauí (PI)}

\author{
Anderson Fontenele Vieira ${ }^{2}$ \\ José Luís Lopes Araújo ${ }^{3}$
}

\begin{abstract}
Resumo: A comunidade de Barra Grande, destino turístico localizado no município de Cajueiro da Praia, Piauí (PI), foi objeto de investigação deste estudo. $O$ turismo nesta região cresceu gerando mudanças estruturais, sociais e ambientais. O objetivo da pesquisa foi analisar os impactos ambientais do turismo em Barra Grande considerando os Indicadores de Sustentabilidade Ambiental (ISA) do IBGE (Instituto Brasileiro de Geografia e Estatística). Foi realizado levantamento bibliográfico e documental sobre as políticas públicas de turismo e meio ambiente, além da aplicação de entrevistas semiestruturadas com dezoito meios de hospedagem diagnosticando três indicadores: abastecimento de água, esgotamento sanitário, e coleta e destinação de resíduos sólidos, que mensuraram parâmetros de pressão (impactos) ao meio natural, qualificaram o estado desse meio e a existência de mecanismos de reposta na minimização dos impactos. A relevância científica consiste na análise da sustentabilidade, por meio de indicadores embasados no Modelo PER (Pressão-Estado-Resposta), adotado pela OECD (Organização para a Cooperação e Desenvolvimento Econômico), de modo a conduzir ações estratégicas para solucionar os problemas ambientais. Quanto aos resultados preliminares, percebeu-se, que as políticas apresentam parte das suas normatizações não empreendidas na prática. No tocante a coleta de campo nos meios de hospedagem, identificou-se que estes estão de acordo com dois dos parâmetros qualitativos avaliados, comprovando que o destino precisa melhorar quanto a sustentabilidade. Por fim, espera-se que os dados possam contribuir no planejamento turístico, além de construir elementos para subsidiar discussões, novas abordagens de pesquisa sobre a viabilidade e adesão de segmentos turísticos sustentáveis no contexto do estado do Piauí ou de outras regiões do Brasil.
\end{abstract}

Palavras-Chave: Turismo. Meio Ambiente. Políticas Públicas. Sustentabilidade. Indicadores.

1 Trabalho resultante da qualificação a ser defendida, pelo primeiro autor, no Programa de Pós-Graduação Regional em Desenvolvimento e Meio Ambiente da Universidade Federal do Piauí (UFPI), tendo sido orientado pelo segundo autor. O referido trabalho apresenta os resultados preliminares da dissertação. Agradecimentos: ao Conselho Nacional de Desenvolvimento Científico e Tecnológico (CNPq).

2 Bacharel em Turismo pela Universidade Federal do Piauí (UFPI). Especialista em Turismo pela Faculdade Internacional Signorelli (FIS). Mestrando em Desenvolvimento e Meio Ambiente pela Universidade Federal do Piauí (UFPI). Bolsista de Mestrado do CNPq. E-mail: anderson_ufpi@hotmail.com.

3 Licenciado em Geografia pela Universidade Federal do Piauí (UFPI). Mestre em Geografia pela Universidade Federal de Pernambuco (UFPE). Doutor em Geografia Humana pela Universidade de São Paulo (USP). Professor dos Programas de Pós-Graduação em Desenvolvimento e Meio Ambiente, e Geografia da Universidade Federal do Piauí (UFPI). E-mail: jlla@ufpi.edu.br. 
Abstract: The community of Barra Grande, tourist destination located in Cajueiro da Praia, Piaui (PI), was the object of investigation of this study. Tourism, in this region, increased creating structural, social and environmental change. The aim of the research was to analyze the environmental impacts of tourism in Barra Grande considering the Environmental Sustainability Indicators of BIGS (Brazilian Institute of Geography and Statistics). It was conducted a bibliographic and documentary survey about public politics for tourism and environment, besides the application of semi-structured interviews with eighteen hotels diagnosing three indicators: water supply, sewage disposal, and collection and disposal of solid waste which measure pressure parameters (impacts) to the natural environment, qualified the state of that environment and the existence of response mechanisms to minimize the impacts. The scientific relevance consists in the analysis of sustainability through indicators based on Model PER (Pressure-State-Response), adopted by OECD (Organization for Economic Cooperation and Development), in order to conduct strategic actions to solve environmental problems. Regarding the preliminary results, it realizes that the policies have part of their normalizations not carried out in practice. Concerning the field collection in the hotels it was identified that they agree with two of evaluated qualitative parameters, proving that the destination needs to improve as sustainability. Finally, it is expected that data may contribute to tourism planning, as well as building elements to support discussions, new research approaches on the viability and adherence of sustainable tourism segments in Piaui context or in other regions of Brazil.

Keywords: Tourism. Environment. Public Policy. Sustainability. Indicators.

Resumen: La comunidad de Barra Grande, destino turístico situado en el municipio de Cajueiro da Praia, Piauí (PI), fue investigado en este estudio. El turismo en esta región creció la generación de cambio estructural, social y ambiental. El objetivo de la investigación fue analizar los impactos ambientales del turismo en Barra Grande considerando los Indicadores de Sostenibilidad Ambiental (ISA) del IBGE (Instituto Brasileño de Geografía y Estadística). Se Ilevó a cabo la encuesta bibliográfica y documental sobre las políticas públicas para el turismo y el medio ambiente, además de la aplicación de entrevistas semiestructuradas con dieciocho alojamientos diagnóstico de tres indicadores: abastecimiento de agua, evacuación de aguas residuales, y la recogida y eliminación de residuos sólidos, los cuales miden parámetros presión (impactos) para el medio ambiente natural, describen el estado de ese ambiente y la existencia de mecanismos de respuesta para minimizar los impactos. La relevancia científica es el análisis de la sostenibilidad a través de indicadores a tierra en modelo PER (Presión-Estado-Respuesta), adoptada por la OCDE (Organización para la Cooperación y el Desarrollo Económico), a fin de impulsar acciones estratégicas para resolver los problemas ambientales. En cuanto a los resultados preliminares, se observó que las políticas tienen parte de sus normas no llevadas a cabo en la práctica. En cuanto a la colección de campo en las instalaciones del alojamiento identificados que éstos están en línea con dos de los parámetros cualitativos evaluados, lo que demuestra que el destino tiene que mejorar la sostenibilidad. Por último, se espera que los datos pueden contribuir a la planificación del turismo, además de la construcción de elementos para apoyar los debates, los nuevos enfoques de investigación sobre la viabilidad y la adhesión de los segmentos de turismo sostenible en el estado de Piauí o en otras regiones de Brasil.

Palabras Clave: Turismo. Medio ambiente. Políticas Públicas. Sostenibilidad. Indicadores.

\section{INTRODUÇÃO}

O setor de serviços é um dos que mais se destaca na geração de recursos financeiros para economia mundial, em janeiro de 2015, por exemplo, registrou no Brasil um crescimento nominal de $1,6 \%$, na comparação com igual mês do ano anterior, inferior às taxas de dezembro (4,0\% revisada) e novembro (3,7\%), a taxa acumulada em 12 meses atingiu 5,4\% Instituto Brasileiro de Geografia e Estatística [IBGE] (2015). O turismo pertence a este setor e tem sido discutido como uma ferramenta capaz de empreender desenvolvimento em diversos aspectos (econômicos, estruturais e sociais), sendo seu maior benefício junto à economia, com - a inserção da população local no mercado de trabalho, geração de novos postos de emprego (diretos e indiretos), aumento do Produto Interno Bruto (PIB) da região e estímulo a novos investimentos em infraestrutura básica e complementar. 
Compreende-se, que a atividade turística tem relação direta com o meio ambiente, uma vez, que se apropria dos recursos naturais com a intenção de comercializá-los, enquanto serviços para obter retorno econômico. Diante desse viés, ressalta-se a articulação conjunta das políticas públicas ambientais e de turismo, no sentido, de regular com ações que focalizem o desenvolvimento sustentável nos processos produtivos, para que não haja tanta degradação e que seja possível exercer essa atividade com fins lucrativos visando salvaguardar os bens do sistema ambiental.

Implementar modelos gerenciais do turismo, que contemplem ações em defesa ao meio ambiente é pensar de forma planejada e racional, valorizando este, que é um dos elementos que atraem visitantes as regiões turísticas. Sendo assim, a gestão pública, o trade turístico ${ }^{4}$ e os demais atores da sociedade civil das comunidades receptoras devem ser conscientes dos impactos positivos e negativos gerados. Neste contexto, Beni (2006) descreve o turismo como um sistema aberto e complexo, o qual deve ser gerenciado por meio da relação de causas e efeitos da sua operacionalização.

A Organização Mundial do Turismo [OMT] $(1997,2003)$ aponta como componente central no processo de planejamento e gerenciamento turístico, a definição e uso de indicadores de sustentabilidade, o que torna possível monitorar as mudanças ao longo dos tempos de maneira constante e consciente, orientando quando é necessário agir ou alterar as políticas públicas. A identificação e escolha desses indicadores são etapas relevantes na análise da sustentabilidade turística, a partir deles, é possível gerar um conjunto de informações para definição das ações futuras a serem adotadas com práticas sustentáveis (OMT, 1997, 2003).

A comunidade de Barra Grande, destino turístico localizado no município de Cajueiro da Praia, Piauí (PI), foi objeto de investigação deste estudo. O turismo nesta região cresceu gerando mudanças estruturais, sociais e ambientais com: a implementação de políticas de turismo em todas as esferas governamentais, a construção de grandes empreendimentos hoteleiros (pousadas, hoteis e resorts ${ }^{5}$ ), a chegada de estrangeiros com interesse de residir na comunidade, o aumento da especulação imobiliária e a participação dos moradores em alguma atividade que tenha relação com o turismo mesmo que não diretamente.

A relevância e impacto científico consistiram na análise da sustentabilidade ambiental através de indicadores embasados no Modelo PER (Pressão-Estado-Resposta), adotado pela OECD (Organização para a Cooperação e Desenvolvimento Econômico), que apresentam a pressão dos agentes humanos exercida no meio natural, qualificam o estado atual deste e a existência de mecanismos de resposta por parte da sociedade, de modo a conduzir ações estratégicas para solucionar os problemas ambientais (Almeida, 2010; Trentin \& Sansolo, 2006).

Do ponto de vista da gestão e planejamento do turismo, esse tipo de monitoramento constitui um instrumento eficaz, com foco direcionado para a sustentabilidade ambiental dos destinos turísticos, além do melhoramento das políticas de turismo e meio ambiente (Macêdo \& Ramos,

4 Conjunto de organizações privadas envolvidas na cadeia produtiva do turismo. (De SOUZA, 2013).

5 Hotel com infraestrutura de lazer e entretenimento que disponha de serviços de estética, atividades físicas, recreação e convívio com a natureza no próprio empreendimento (De SOUZA, 2013). 
2012). Para isso, foram escolhidos três indicadores ambientais estabelecidos pelo Estudo de Desenvolvimento Sustentável (EDS) do Instituto Brasileiro de Geografia e Estatística (IBGE), identificando o nível de impacto ao meio ambiente do abastecimento de água, esgotamento sanitário e coleta e destinação final do lixo (IBGE, 2012).

Dessa forma, buscando atender aos questionamentos e hipótese propostos, elencou-se como objetivo geral - analisar os impactos ambientais do turismo em Barra Grande considerando os indicadores de sustentabilidade ambiental do IBGE; e como objetivos específicos - identificar os impactos do turismo ao meio ambiente gerados pelos meios de hospedagem, utilizando os indicadores ambientais de saneamento (abastecimento da água, coleta e destinação final dos resíduos sólidos e esgotamento sanitário), propostos pelo IBGE, 2012; e verificar a efetividade das ações de conservação e preservação do ambiente natural nas políticas públicas (federais, estaduais e municipais) para o desenvolvimento turístico local.

\section{PROCEDIMENTOS METODOLÓGICOS}

Foram realizadas visitas in loco na Secretaria Estadual de Meio Ambiente e Recursos Hídricos (SEMAR), localizada em Teresina (PI), no Instituto Brasileiro do Meio Ambiente e dos Recursos Naturais Renováveis (IBAMA), no Instituto Chico Mendes de Conservação da Biodiversidade (ICMBIO), localizados em Parnaíba (PI), na Secretaria Estadual de Turismo (SETUR), localizada em Teresina (PI) e na Prefeitura de Cajueiro da Praia (PI), que irão contribuir para o levantamento documental. Além de pesquisas nos principais bancos internacionais e nacionais de dados em busca de estudos indexados, teses e dissertações correlatas ao tema.

Quanto às técnicas de pesquisa, o levantamento dos dados qualitativos foi realizado através da aplicação de entrevistas semiestruturadas e específicas com: o Secretário municipal de Turismo e Meio Ambiente de Cajueiro da Praia e os proprietários ou gestores dos meios de hospedagem. Destaca-se que as entrevistas fornecerem informações sobre as políticas públicas de turismo e meio ambiente, além de dados dos indicadores de saneamento propostos como parâmetros nos meios de hospedagem.

No tocante a amostra, optou-se por trabalhar com os meios de hospedagem, em virtude, da pressão que exercem no núcleo urbano pelo uso da água, pela produção de esgoto, e produção e destinação dos resíduos sólidos. Em um primeiro momento, foram delimitados todos os meios cadastrados na prefeitura municipal, selecionados por corresponderem à capacidade de leitos regulares oferecidos. Porém, durante a pesquisa de campo constatou-se que muitos empreendimentos de médio porte, que apresentavam capacidade relativa de leitos não eram formalizados enquanto empresa, fato que, diminuiria de forma significativa a amostra. Pensando em não comprometer os resultados e torná-los mais fidedignos, estabeleceu-se uma amostra correspondente a população dos meios de hospedagem de Barra Grande. De acordo com o Secretário de Turismo, não se tem a informação do quantitativo de hospedagens e nem das características de seus servi- 
ços, sendo esse banco de dados elaborado pelo pesquisador mais uma contribuição social ao munícipio.

As informações coletadas sobre os indicadores nos meios de hospedagem foram agrupadas em um quadro, qualificando o diagnóstico destes. Abordou-se, como cada uma das pousadas pesquisadas operavam com o manejo da água, produção dos dejetos e a eliminação do lixo proveniente das atividades internas. Posteriormente, foram feitas as análises e discussões da situação diagnosticada, comparando-a, com os parâmetros estabelecidos como adequados pelo IBGE. Concluindo-se, que a maior parte dos empreendimentos locais estão realizando suas ações operacionais dentro da perspectiva do estudo utilizado como instrumento metodológico.

Por fim, elaborou-se um diagnóstico geral para se compreender os impactos ambientais consequentes da operacionalização dos serviços dos meios de hospedagem participantes do estudo, através da aplicação da metodologia PER, desenvolvida e recomendada originalmente pela OECD, 1993, e também utilizada com algumas alterações por outras agências internacionais como Unstat (Divisão de Estatísticas das Nações Unidas) e Eurostat (Divisão de Estatísticas da Comunidade Europeia). De maneira geral, o modelo busca descrever a dinâmica de um problema ambiental; por exemplo, a pressão ambiental decorrente da deposição de esgotos em um rio. Tais pressões alteram o estado do sistema ambiental, reduzindo a qualidade da água ou a diversidade de espécies. Essas alterações, por seu turno, conduzem, em alguns casos, a respostas dos governos ou das instituições (entre os quais, o próprio mercado) (Tayra \& Ribeiro, 2006).

\section{DESENVOLVIMENTO SUSTENTÁVEL (DS) E POLÍTICAS PÚBLICAS}

\subsection{Políticas Públicas e a Inter-Relação com o Desenvolvimento Sustentável (DS)}

A gestão pública no contexto atual tem como um de seus objetivos empreender princípios norteadores e normas regulatórias para gerir as diferentes esferas estatais conduzindo a ações assertivas e coerentes com as demandas, particularidades daquele determinado território. Dessa maneira, "a função que o Estado desempenha em nossa sociedade sofreu inúmeras transformações ao passar do tempo. No século XVIII e XIX, seu principal objetivo era a segurança pública e a defesa externa em caso de ataque inimigo" Serviço de Apoio às Micro e Pequenas Empresas [SEBRAE] $(2008$, p. 5). Mas com o aprofundamento da democracia nas gestões governamentais, interferindo diretamente nas relações sociedade e cidadãos, as responsabilidades do Estado se projetaram em ações mais amplas para atender as diferentes áreas da esfera social, como: saúde, educação, segurança, lazer e meio ambiente.

Para atingir resultados satisfatórios nas diversas áreas e promover o bem-estar da sociedade, objetivo prioritário dos governos, esses utilizam as políticas públicas que podem ser definidas da seguinte forma: "[...] conjunto de ações e decisões do governo, voltadas para a solução (ou não) de problemas da sociedade [...]" (SEBRAE, 2008, p. 5). Dentro dessa perspectiva, precisa-se pensar que o Estado é dividido em três esferas: federal, estadual e municipal, que cada uma delas 
têm suas responsabilidades individualizadas e interligadas, de modo que, a tomada de decisão possa ser coerente e efetiva garantindo o bem-estar social assegurado.

De acordo com Bobbio, Matteucci e Pasquino (1998, p. 954), a política se qualifica por:

[...] atos como o ordenar ou proibir alguma coisa com efeitos vinculadores para todos os membros de um determinado grupo social, o exercício de um domínio exclusivo sobre um determinado território, o legislar através de normas válidas erga omnes, o tirar e transferir recursos de um setor da sociedade para outros, etc; outras vezes ela é objeto, quando são referidas à esfera da Política ações como a conquista, a manutenção, a defesa, a ampliação, o robustecimento, a derrubada, a destruição do poder estatal, etc.

De Faria (2003, p. 22) apresenta a seguinte afirmação, “[...] há hoje uma Babel de abordagens, teorizações incipientes e vertentes analíticas que buscam dar inteligibilidade à diversificação dos processos de formação e gestão das políticas públicas [...]". De acordo com esse, vive-se em um mundo cada vez mais caracterizado pela interdependência, incerteza e complexidade quanto às questões que demandam regulação, onde o conhecimento assume lugar de destaque (De Faria, 2003).

Para Becker (2001) o desenvolvimento sustentável surge como uma reestruturação da sociedade frente à atual crise, e que a sustentabilidade é ou deveria ser uma ideologia a ser expressa nas políticas, nos projetos públicos e nas ONG's da sociedade civil. Com a globalização, o papel do Estado sofreu alterações significativas, como a descentralização decisória, porém é necessário que seja redefinido, uma vez que sua importância não foi reduzida, devendo coordenar e regular as políticas, assim como direcionar e intervir em conflitos (Trentin \& Sansolo, 2006).

Nota-se que em alguns casos, as decisões relativas à gestão territorial são tomadas por quem desconhece a realidade local e, via de regra, impõem condições para o desenvolvimento baseando-se em experiências obtidas em contextos socioeconômico, político e cultural diferentes, replicando uma ação que não se adeque a dinâmica daquele local. Sendo assim, pode-se afirmar que a concretização do desenvolvimento sustentável esbarra em vários fatores, um deles está relacionado diretamente ao papel do Estado e das políticas públicas implantadas (Trentin \& Sansolo, 2006).

Entretanto, os componentes básicos da sustentabilidade do desenvolvimento exigem exatamente um mercado regulamentado para o longo prazo. Isso explica, entre outras razões, por que atores e variáveis tais como "gerações futuras" ou "longo prazo" são estranhos ao mercado que focaliza suas metas para o curto prazo. O mesmo se aplica, ao tipo específico de escassez atual de recursos naturais enfrentada no mercado, elementos como: o equilíbrio climático, a camada de ozônio, a biodiversidade ou a capacidade de recuperação do ecossistema transcendem a ação mercadológica (Trentin \& Sansolo, 2006).

Guimarães (2001) faz análise crítica a uma inversão de papeis atual, onde a responsabilidade desenvolvimentista do Estado está sendo atribuída ao mercado, e afirma ainda, que o desenvolvimento sustentável necessita da corresponsabilidade dessas duas esferas no controle do planejamento e efetividade do desenvolvimento. Para isso, reflexões são importantes na condução 
da melhor estratégia definida, como: se os recursos naturais estão escassos, mas ainda atendem às necessidades atuais do mercado, por que se preocupar com tais recursos no longo prazo? $A$ ciência suprirá as necessidades dispondo de novas tecnologias ou produtos substitutos?

Sendo atribuição do Estado a elaboração de políticas públicas, estas são aplicadas em um determinado território, podendo ser município, região ou país. Portanto, Guimarães (2001, p. 49) coloca que um dos principais desafios das ações políticas diz respeito à:

[...] necessidade de territorializar a sustentabilidade ambiental e social do desenvolvimento - o "pensar globalmente, mas atuar localmente" - e, ao mesmo tempo, dar sustentabilidade ao desenvolvimento do território, ou seja, fazer com que as atividades produtivas contribuam efetivamente para o aperfeiçoamento das condições de vida da população e protejam o patrimônio biogenético a ser transmitido às gerações futuras (Guimarães, 2001, p. 49).

Esse critica o contexto atual do desenvolvimento sustentável, por ser um discurso pouco colocado em prática, imperando as necessidades do mercado em detrimento do posicionamento do Estado. Nessa mesma linha, Guimarães (1998, p. 71 apud Guimarães \& Feichas, 2009, p. 314) faz uso de uma equação, em que a sustentabilidade de dado território sofre a influência de cinco dimensões inter-relacionadas e que se expressam pela equação POETA, onde:

P - significa população em suas diferentes especificidades (tamanho, composição, densidade, dinâmica demográfica); O - organização social (padrões de produção, estratificação social, padrão de resolução de conflitos); E - entorno (ambiente físico e construído, processos ambientais, recursos naturais); T - tecnologia (inovação, progresso técnico, uso de energia); e A - aspirações sociais (padrão de consumo, valores, cultura). Para avaliação do desenvolvimento regional e seu progresso, [...] propõe indicadores em nove áreas: 1) existência de recursos naturais, 2) existência de atores sociais organizados, 3) existência de instituições locais para o desenvolvimento do território, 4) tipos de procedimentos para o desenvolvimento regional, 5) mudanças de cultura, 6) fortalecimento da cultura de confiança entre os atores, 7) capacidade de negociação dos atores locais, 8) acumulação de capital endógeno, 9) acumulação endógena de conhecimento e progresso técnico. (Guimarães; Feichas, 2009, p. 314).

Na verdade, a equação POETA indica alguns elementos que podem promover a sustentabilidade num determinado território, desde que projetados e atingidos por meio de políticas públicas e planejamento. No que se refere à concentração de pessoas em ambientes urbanos e a gestão dos problemas, a Comissão Mundial sobre Meio Ambiente e Desenvolvimento [CMMAD] (1988) alerta para importação e cópia de modelos muitas vezes implantados em locais com condições socioeconômicas e culturais diferentes comprometendo sua aplicabilidade naquele contexto.

É interessante contextualizar como iniciou a idealização pelo desenvolvimento sustentável para que se possa entender essa mudança paradigmática. Durante a década de 1960 emergiu nos Estados Unidos e Europa um enfoque maior para preocupação ambiental, motivada por movimentos político-sociais que questionavam, dentre outras coisas, os padrões de estilo de vida e o consumismo vigentes (Gonçalves, 1989). Preocupações dos países desenvolvidos relacionadas às atividades industriais, à ocupação do espaço e à geração de energia, face já terem resolvido os pro- 
blemas de atendimento às necessidades básicas de suas populações, mas que eram vistas nos países em desenvolvimento como um modismo (Gonçalves, 1989).

Estes últimos lidavam com menos prioridade para questão ambiental, pois tinham as necessidades básicas de suas populações como primordial, uma vez que, problemas como: fome, miséria, doenças infectocontagiosas e geração de emprego/renda eram tão comuns. Em fins dos anos de 1960, com a divulgação de estudos impactantes sobre os problemas relativos ao uso excessivo e a finitude dos recursos naturais, bem como ao aumento populacional é que a temática ambiental se fortaleceu no restante do mundo. Fatores como o descarte dos resíduos e os níveis de poluição derivados da produção e consumo mundiais suscitaram discussões sobre os rumos do desenvolvimento (Gonçalves, 1989).

Dentre os estudos convém destacar "The limits to growth (Meadows et al., 1972)", que gerou maior repercussão no sentido de mudança de comportamento frente ao meio ambiente e aos efeitos do modelo de crescimento econômico. O relatório publicado por um grupo de cientistas, representando simulações matemáticas, apresentou projeções alarmantes quanto às formas e os níveis de produção/consumo de alimentos e os impactos no aumento da miséria e fome (Nobre, 2002). Basicamente o documento questionava a relação entre a lógica de crescimento econômico e de utilização dos recursos naturais, como solução, propunha o congelamento do ritmo de crescimento populacional para se alcançar estabilidade nos aspectos econômicos e ecológicos (Swarbrooke, 2000).

Os estudos divulgados e a preocupação sobre os rumos do crescimento mundial levaram a Organização das Nações Unidas (ONU) a debater ações integradas para um modelo de desenvolvimento global, socialmente justo, equilibrando ecologia e economia. Destaca-se a Conferência das Nações Unidas sobre o Meio Ambiente e Desenvolvimento (CNUMAD), em Estocolmo (1972), considerada decisiva para a evolução do ambientalismo mundial (Swarbrooke, 2000). De um lado, os países ricos e industrializados defendiam a implantação de controles rigorosos das emissões de poluentes e do crescimento global. Do outro, os países pobres e em desenvolvimento não aceitavam essa imposição ao seu crescimento econômico.

De fato, o marco efetivo para a incorporação da questão ambiental foi a Conferência das Nações Unidas sobre o Meio Ambiente e Desenvolvimento (CNUMAD) ou (Rio-92), que reuniu mais de 170 chefes de estado, teve ampla cobertura de mídia e trouxe o meio ambiente para o centro das discussões mundiais (De Oliveira, 2013). Contudo, existem críticas quanto aos resultados desta, pois a maioria dos acordos foram conduzidos para serem estruturas de ação, do que instrumentos efetivos de impulso para as mudanças necessárias, consistindo em cartas de intenções sem a definição precisa de prazos e metas (Gonçalves, 1989).

Já a Conferência das Nações Unidas sobre Desenvolvimento Sustentável (CNUDS) ou (Rio+20), realizada em 2012, gerou um compromisso político das nações para que até 2015 ocorre-se uma mobilização mundial ao estabelecimento de objetivos de desenvolvimento sustentável, reconhecendo a pobreza como o maior desafio. O evento ocorreu em meio a uma crise econômica na Europa, que gerou menor adesão dos líderes mundiais e teve resultados abaixo do esperado 
pelos atores sociais, comunidade científica internacional e sociedade civil organizada (De Oliveira, 2013).

\subsection{Turismo: uma Oportunidade de Desenvolvimento}

As políticas públicas de turismo e meio ambiente, no caso do Brasil, são ícones que devem ser desenvolvidos conjuntamente optando por um segmento turístico sustentável e com bases ideológicas ambientais conservacionistas, uma vez que, os recursos naturais são parte importante do produto ofertado. Um exemplo disso aconteceu com a elaboração das Diretrizes para a Política Nacional de Ecoturismo, em 1994, que foi discutida por um grupo interministerial com membros do Ministério da Indústria e Comércio (MICT) e Ministério do Meio Ambiente, dos Recursos Hídricos e da Amazônia Legal (MMA), mostrando que essa integração das instituições no âmbito governamental aperfeiçoa a gestão e o controle para efetivação dos resultados necessários de determinada ação (política) (Trentin \& Sansolo, 2006).

Os Indicadores de Desenvolvimento Sustentável (IDS) são instrumentos norteadores para elaboração das políticas públicas desenvolvimentistas, existem várias abordagens metodológicas internacionais organizadas e aplicadas por diferentes instituições (IBGE, 2012). No Brasil, o IBGE publicou em 2002, 2004, 2008 e 2010, os IDS categorizados em econômicos, sociais, ambientais e institucionais, estes, "[...] viabilizam o acesso integrado à informação já disponível sobre temas relevantes para o desenvolvimento, assim [...] apontam a necessidade de geração de novas informações." (IBGE, 2012, p. 11). Merico (2001) vê na política ambiental baseada em indicadores, uma aliada para avaliar o nível de sustentabilidade do processo econômico e social, pois

A construção desses indicadores pode subsidiar a implantação de políticas associadas a melhorias dos padrões avaliados. O objetivo é influenciar a atividade econômica/social de tal maneira que foi aplicado no município de Blumenau (SC) e envolveu a criação de um gráfico de sustentabilidade, conhecido como Sustentômetro, [...] (Merico, 2001, p. 258).

Esse relata que a experiência de Blumenau consistiu na criação de uma série de indicadores para avaliar continuamente as políticas públicas de meio ambiente, visualizando a evolução do aspecto ambiental em direção à sustentabilidade, e permitindo que a população conhecesse a dinâmica de sua cidade para poder influenciar nela. O Índice de Sustentabilidade para Blumenau (ISB) tem como objetivo avaliar a situação real do ambiente no município e serve como subsídio para tomada de decisão, pois agrega uma série de indicadores ambientais que anualmente apresentam a evolução em direção ao desenvolvimento sustentável (Merico, 2001).

Exemplos como esse, são válidos para mostrar que o papel indutor do Estado está relacionado aos instrumentos econômicos, por exemplo, dentro da atividade de serviços prestada pelos meios de hospedagem, este pode reduzir tributos incentivando aos que economizarem energia, reduzirem o consumo de água, tratarem o lixo produzido, entre outros itens que podem trazer benefícios ambientais (Tentrin \& Sansolo, 2006). Nesse caso, o Estado tem os instrumentos legais como: a legislação, os mecanismos de criar e alterar leis, a determinação de zoneamento econô- 
mico-ecológico, a necessidade de licenciamento de empreendimentos turísticos, entre outros aspectos (Tentrin \& Sansolo, 2006).

Sabe-se que o desenvolvimento tem como um de seus propulsores a economia gerada pelas mais diversas atividades. $O$ turismo é um dos segmentos econômicos brasileiros que vêm passando por alto crescimento nos últimos anos, e como observado pelo Ministério do Turismo [MINTUR] (2012), a posição do Brasil evoluiu de forma significativa no concorrido ranking da OMT, como destino turístico mais demandado do mundo (MINTUR, 2012).

Segundo o MINTUR (2012), o Brasil ocupa a 40a posição no ranking de receita turística internacional ao registrar US\$ 6,6 bilhões, sendo advindas de recursos estrangeiros, no ano de 2012. Nos primeiros lugares encontram-se destinos consagrados, como: os Estados Unidos em primeiro, seguido de Espanha e França. Entre as economias emergentes, a China é o país que mais cresce e ocupa a quarta colocação, seguida pela Tailândia, em sétimo lugar.

O Plano Nacional de Turismo (PNT) revela que o PIB (Produto Interno Bruto) turístico brasileiro encontra-se na sexta posição no ranking mundial do World Trade Tourism Council [WTTC], apenas atrás de Estados Unidos, China, Japão, França e Itália, e o governo faz previsões otimistas para alcançar a terceira colocação depois dos grandes eventos da Copa do mundo de 2014 e das Olímpiadas, em 2016. De acordo com a previsão do relatório do WTTC (2013), o Brasil deverá ultrapassar a França até 2022, mas o governo brasileiro prevê a terceira colocação, à frente, ainda do Japão (PNT, 2013).

De acordo com (MINTUR, 2012), a participação do turismo na economia nacional já representa 3,7\% do PIB. De 2003 a 2009 o setor cresceu 32,4\% enquanto a economia brasileira apresentou expansão de 24,6\% (MINTUR, 2012). Apesar desses dados que mostram que o turismo nacional tem apresentado boas projeções, infere-se que por sua dimensão continental, situação geográfica e a rica atratividade natural, cultural, e histórica, deve haver união de esforços entre todos os envolvidos com a cadeia turística, visando garantir uma posição mais competitiva.

A área ambiental merece dedicada atenção na busca pela qualidade dos serviços ofertados e vem ganhando expressão como diferencial competitivo no mercado mundial, tanto pelas empresas como pelos destinos turísticos (Donaire, 1995). A atividade turística, nos seus mais diversos segmentos, tem vasto potencial poluidor, especialmente quando desenvolvida sem planejamento e visando apenas ganhos econômicos. Poluição visual, sonora, de aquíferos, atmosférica, descaracterização ambiental, comprometimento no abastecimento de água, energia elétrica são alguns exemplos de impactos negativos gerados pelo turismo (Donaire, 1995).

De acordo com De Oliveira (2013), o turismo possui por características a intersetorialidade, ser captador de investimentos e gerador de emprego/renda. No entanto, somente passou a ser entendido como um segmento econômico nos anos de 1970, com o crescimento significativo do turismo de massa para destinos que apresentam potencial turístico, seguida de estagnação até meados dos anos de 1990, e novo impulso a partir da segunda metade da década. Os principais fatores para tal foram: o aumento de renda da população; a consolidação da democracia; abertura da economia; a realização da Conferência das ONU sobre Meio Ambiente e Desenvolvimento (Rio- 
92), que gerou divulgação de mídia para o país; a estabilidade monetária com o Plano Real; e, a ampliação da rede de hospedagem (Beni, 2006).

Em contraste com o crescimento global e os esforços para expansão do turismo mundial, ocorreu outro período de estabilidade no fluxo turístico nacional. A partir de 2005, ano do maior número de chegadas (5.358.170), se verifica que o número de turistas estrangeiros evoluiu e os principais países emissores no período de 2006 a 2010 foram: Argentina, Estados Unidos, Itália, Uruguai, Alemanha, Chile, França, Paraguai, Portugal e Espanha (MINTUR, 2012). Contudo, ao longo da década a média anual de chegadas ficou em 4,8 milhões e a participação do país no fluxo turístico mundial ficou em média pouco acima de meio por cento, com tendência de redução de sua participação durante quase todo período.

A estabilidade no número de chegadas de turistas internacionais no país de 2001 a 2010 foi relativa, pois no tocante a geração de receita cambial e a participação do Brasil no fluxo turístico mundial, duas situações contrastantes ocorreram. De um lado, houve crescimento constante na receita cambial gerada pelo setor, com média anual de quase US\$4 bilhões, com pico no ano de 2010 de US\$5,92 bilhões. De outro, ocorreu redução da participação do país no total mundial de 0,70\% para 0,54\%, com média em 0,59\% (MINTUR, 2012).

Em 2011, as atividades características do turismo geraram $\mathrm{R} \$ 131,76$ bilhões de valor adicionado na economia do país e mais de 8,11 milhões de postos de trabalho. Os serviços de hospedagem representaram ao todo, dentre as atividades características do turismo, 3,24\% do valor adicionado e 4,25\% dos postos de trabalho (MTUR, 2012). Entende-se que o atual cenário macroeconômico do país encontra-se favorável a maioria dos setores produtivos, pois aponta uma fase de crescimento econômico, após a retração derivada da crise mundial de 2008-2009 (De Oliveira, 2013).

\section{CARACTERIZAÇÃO DOS MEIOS DE HOSPEDAGEM (MH) QUANTO AOS INDICADORES AMBIEN- TAIS}

Nesta secção serão apresentados os resultados do levantamento de campo nos 18 meios de hospedagem, que participaram da pesquisa, de 25 que foram visitados. Estes foram selecionados aleatoriamente, no período de 04 de maio a 17 de julho de 2015, utilizou-se desse critério, pois na prefeitura e secretária de Turismo do município de Cajueiro da Praia não existem dados registrados que comprovem o quantitativo de pousadas da comunidade de Barra Grande. A figura 1 representa um mapa das pousadas abordadas pela pesquisa. 
Figura 1 - Mapa das Pousadas de Barra Grande

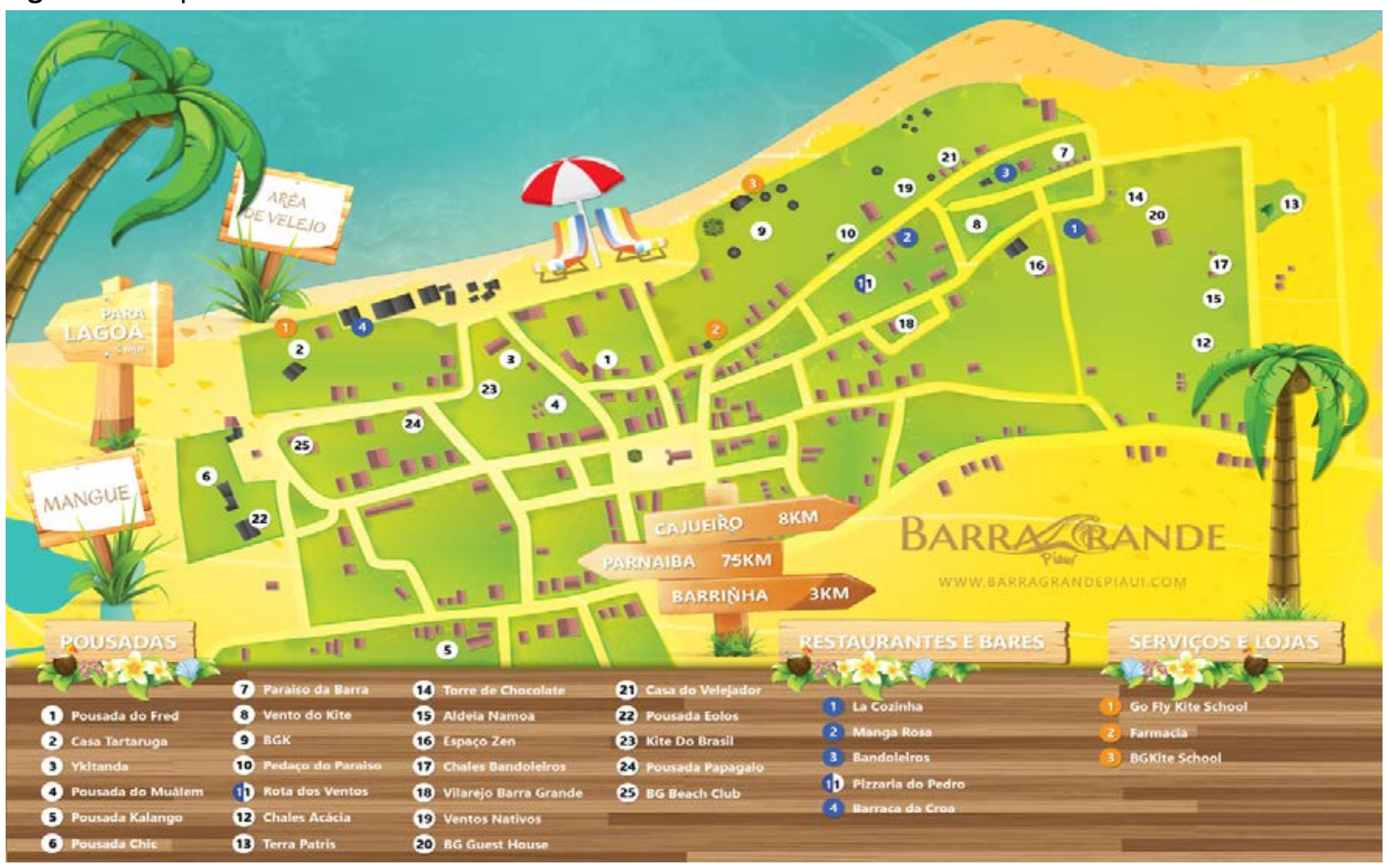

Fonte: (BARRATUR, 2015)

Os meios de hospedagem selecionados representam aproximadamente $80 \%$ dos leitos disponibilizados para o turista em Barra Grande, comprovando a pressão, que exercem no meio natural quando estão com sua capacidade de lotação máxima. Os empresários hoteleiros foram questionados quanto a serem avaliados por algum programa de qualidade ambiental, dos 18, 12 afirmaram que sim, pelo Selo de Sustentabilidade Ambiental para os Meios de Hospedagem do SEBRAE/PI. Este selo segue os parâmetros do Programa Nacional de Certificação em Turismo Sustentável (PCTS), que estabelece critérios mínimos de sustentabilidade nestes estabelecimentos, baseado na Norma Brasileira 15.401:2006 (SEBRAE, 2015).

Essa informação mostrou que existem instituições públicas atuando com os meios de hospedagem locais, focalizando em ações políticas favoráveis à gestão da sustentabilidade. Além do que, mais da metade está dentro dos parâmetros estabelecidos como ideais pelo selo, comprovando que existe nos gestores hoteleiros, a compreensão para esse modelo gerencial comprometido com a sustentabilidade.

O quadro 1 apresenta o diagnóstico dos 18 meios de hospedagem participantes, quanto aos indicadores do IBGE (2012): água, destino dos resíduos sólidos e esgotamento sanitário, além de incluir a fonte de energia, por acreditar-se que esse é um indicador eficaz na percepção da minimização de impactos gerados por empresas, independente do segmento em que atuam. Esse levantamento permitiu se entender a dinâmica atual do turismo na comunidade, baseado nas práticas operacionais das pousadas, equipamentos turísticos, necessários para efetividade da atividade em Barra Grande. 
Quadro 1 - Diagnóstico das Pousadas

\begin{tabular}{|c|c|c|c|c|}
\hline $\begin{array}{c}\text { Meio de Hospeda- } \\
\text { gem }\end{array}$ & $\begin{array}{c}\text { Captação de } \\
\text { Água }\end{array}$ & $\begin{array}{c}\text { Destino dos Resí- } \\
\text { duos Sólidos }\end{array}$ & Esgoto & Fonte de Energia \\
\hline $\begin{array}{l}\text { Pousada Paraíso da } \\
\text { Barra }\end{array}$ & $\begin{array}{l}\text { Rede Pública, } \\
\text { Poço Artesiano } \\
\text { e Carro Pipa }\end{array}$ & $\begin{array}{l}\text { Coleta Municipal } \\
\text { Separação de latas, } \\
\text { papeis, vidros e res- } \\
\text { tos de alimentos. }\end{array}$ & Fossa séptica & $\begin{array}{l}\text { Rede Pública } \\
\text { Gerador }\end{array}$ \\
\hline Pousada do Muálem & Poço Artesiano & Coleta Municipal & Fossa Séptica & Rede Pública \\
\hline Pousada Papagaio & Poço Artesiano & $\begin{array}{l}\text { Coleta Municipal } \\
\text { Separação de latas, } \\
\text { papeis, vidros e res- } \\
\text { tos de alimentos. }\end{array}$ & Fossa Séptica & Rede Pública \\
\hline Casa do Velajador & Rede Pública & $\begin{array}{l}\text { Feito pela pousada } \\
\text { (destino lixão) }\end{array}$ & Fossa Séptica & $\begin{array}{l}\text { Rede Pública } \\
\text { Gerador }\end{array}$ \\
\hline $\begin{array}{l}\text { Pousada Aldeia } \mathrm{Na} \\
\text { Moa }\end{array}$ & Rede Pública & $\begin{array}{l}\text { Coleta Municipal } \\
\text { Separação de latas, } \\
\text { papeis, vidros e res- } \\
\text { tos de alimentos. }\end{array}$ & Fossa Ecológica & Rede Pública \\
\hline Pousada Acácia & Rede Pública & Coleta Municipal & Fossa Séptica & Rede Pública \\
\hline $\begin{array}{l}\text { Pousada Torre de } \\
\text { Chocolate }\end{array}$ & $\begin{array}{l}\text { Rede Pública } \\
\text { Poço Artesiano }\end{array}$ & Coleta Municipal & Fossa Séptica & $\begin{array}{l}\text { Rede Pública } \\
\text { Pretende fazer } \\
\text { uma subestação } \\
\text { na pousada }\end{array}$ \\
\hline Pousada Titas & $\begin{array}{l}\text { Rede Pública } \\
\text { Poço Artesiano }\end{array}$ & $\begin{array}{l}\text { Coleta Municipal } \\
\text { Separação do lixo } \\
\text { orgânico }\end{array}$ & Fossa Séptica & $\begin{array}{l}\text { Rede Pública } \\
\text { Gerador }\end{array}$ \\
\hline $\begin{array}{l}\text { Pousada } \\
\text { Terra Patris }\end{array}$ & $\begin{array}{l}\text { Rede Pública } \\
\text { Poço Artesiano }\end{array}$ & $\begin{array}{l}\text { Coleta Municipal } \\
\text { Separação de latas, } \\
\text { papeis, vidros e res- } \\
\text { tos de alimentos } \\
\text { Compostagem }\end{array}$ & $\begin{array}{l}\text { Fossa Séptica } \\
\text { Fossa Ecológica }\end{array}$ & $\begin{array}{l}\text { Rede Pública } \\
\text { Gerador }\end{array}$ \\
\hline Espaço Zen & $\begin{array}{l}\text { Rede Pública } \\
\text { Poço Artesiano }\end{array}$ & Coleta Municipal & Fossa Séptica & Rede Pública \\
\hline Pousada Kalango & $\begin{array}{l}\text { Rede Pública } \\
\text { Poço Artesiano }\end{array}$ & Coleta Municipal & Fossa Séptica & Rede Pública \\
\hline $\begin{array}{l}\text { Pousada Rota dos } \\
\text { Ventos }\end{array}$ & $\begin{array}{l}\text { Rede Pública } \\
\text { Carro Pipa }\end{array}$ & Coleta Municipal & Fossa Séptica & Rede Pública \\
\hline $\begin{array}{l}\text { Pousada Barra Kite } \\
\text { Camp - BGK }\end{array}$ & $\begin{array}{l}\text { Poço Artesiano } \\
\text { Carro Pipa }\end{array}$ & Coleta Municipal & Fossa Séptica & $\begin{array}{l}\text { Rede Pública } \\
\text { Vai implantar } \\
\text { Paineis Solares }\end{array}$ \\
\hline $\begin{array}{l}\text { Pousada Ventos } \\
\text { Nativos }\end{array}$ & $\begin{array}{l}\text { Rede Pública } \\
\text { Poço Artesiano } \\
\text { Carro Pipa } \\
\text { Chuva }\end{array}$ & $\begin{array}{l}\text { Coleta Municipal } \\
\text { Separação de garra- } \\
\text { fas pets dos outros } \\
\text { resídos }\end{array}$ & Fossas Séptica & Rede Pública \\
\hline Pousada Manatí & Caminhão Pipa & $\begin{array}{l}\text { Coleta Municipal } \\
\text { Coleta Seletiva den- } \\
\text { tro da pousada }\end{array}$ & Fossa Séptica & $\begin{array}{l}\text { Rede Pública } \\
\text { Paineis Solares } \\
\text { Gerador }\end{array}$ \\
\hline Pousada do Fred & $\begin{array}{l}\text { Rede Pública } \\
\text { Poço Artesiano }\end{array}$ & Coleta Municipal & Fossa Séptica & $\begin{array}{l}\text { Rede Pública } \\
\text { Gerador }\end{array}$ \\
\hline Pousada Tartaruga & $\begin{array}{l}\text { Rede Pública } \\
\text { Poço Artesiano }\end{array}$ & $\begin{array}{l}\text { Coleta Municipal } \\
\text { Compostagem }\end{array}$ & Fossa Séptica & Rede Pública \\
\hline Pousada Eolos & Poço Artesiano & Coleta Municipal & Fossa Séptica & Rede Pública \\
\hline
\end{tabular}

Fonte: (Vieira, 2015) 


\subsubsection{Indicadores Ambientais de Pressão, Estado e Resposta para Barra Grande}

Os resultados obtidos indicaram que a água é captada em poço artesiano nas 18 pousadas pesquisadas, e possivelmente, nas outras que não estavam funcionando regularmente ou não quiseram participar da pesquisa. Infere-se ainda, que 12 utilizam da rede encanada de Barra Grande, citada por todos como de péssima qualidade, salgada, apresentar coloração e odor, 3 dos proprietários relatou que já foram feitas analises químicas onde identificou-se a presença de coliformes fecais. E 4 disseram que compram carros pipas com uma frequência bastante regular, sobretudo nos períodos de alta estação, correspondendo aos meses de junho a fevereiro, época em que estrangeiros estão de férias e vêm de viagem ao Brasil. Percebeu-se na maioria dos relatos que eles fazem o tratamento por conta própria da água estocada nas cisternas, através da aplicação de cloro e hipoclorito de sódio cedidos pela prefeitura municipal.

Quanto à questão dos resíduos sólidos, apenas uma das pousadas não utiliza da coleta municipal e faz o processo por conta própria. Seis disseram fazer alguma ação de coleta seletiva ou separação de lixo orgânico dos demais resíduos dentro de suas dependências, mesmo afirmando que sabiam que era um trabalho em vão, pois quando o caminhão de coleta do município de Cajueiro da Praia recolhia, encaminhava tudo para um lixão, destino final. Dois estabelecimentos afirmaram fazer compostagem, reaproveitando os resíduos decorrentes de suas atividades. Uma informação relevante, no caso dos meios de hospedagem que fazem a coleta ou separação, é que de alguma forma eles contribuem para inserção da mão de obra daqueles moradores que trabalham com o lixo, no caso dos carroceiros e catadores de lata, que vendem ou fazem transporte daquilo que conseguem nas pousadas.

No referente ao tratamento dos dejetos, sabe-se que Barra Grande não apresenta rede de esgoto. Dezesseis pousadas utilizam da fossa séptica, uma da fossa ecológica e uma outra apresenta as duas modalidades de tratamento. Quanto a esse ponto, uma proprietária de pousada, idealizadora da fossa ecológica, e presidente da Associação dos Hoteleiros disse que tentou fazer um trabalho de sensibilização para que todos aderissem a modalidade de tratamento ecológica, mas segundo ela não houve interesse coletivo.

Por fim, quanto à fonte de energia, todas as pousadas utilizam da elétrica fornecida pela rede pública, sendo que uma delas apresenta painéis solares responsáveis por parte de sua produção. Três empreendedores afirmaram que vão implantar os painéis, mas sem previsão para. Tal fato, comprova um início de percepção da necessidade de se buscar estratégias para a produção de energia mais limpa e sustentável.

No quadro 2, estão relacionados três indicadores ambientais estudados no caso de Barra Grande, que indicam o problema, o estado, o agente de pressão e a resposta. 
Quadro 2 - Avaliação Modelo PER (Pressão-Estado-Resposta)

\begin{tabular}{|l|l|l|l|}
\cline { 2 - 4 } \multicolumn{1}{l|}{} & \multicolumn{3}{c|}{ PARÂMETROS } \\
\hline Problemas & Indicador de Pressão & \multicolumn{1}{c|}{ Indicador de Estado } & Indicador de Resposta \\
\hline Esgoto & $\begin{array}{l}\text { Empreendimentos } \\
\text { turísticos }\end{array}$ & $\begin{array}{l}\text { Perfuração de poços } \\
\text { artesianos }\end{array}$ & Não foi identificado \\
\hline Resíduos sólidos & $\begin{array}{l}\text { Aumento da geração de } \\
\text { efluentes na alta tem- } \\
\text { porada }\end{array}$ & $\begin{array}{l}\text { Diminuição do Índice } \\
\text { de Qualidade da Água }\end{array}$ & Não foi identificado \\
\hline $\begin{array}{l}\text { Aumento da geração de } \\
\text { resíduos na alta tempo- } \\
\text { rada }\end{array}$ & $\begin{array}{l}\text { Existência de lixão } \\
\text { como destino inade- } \\
\text { quado dos resíduos. }\end{array}$ & Não foi identificado \\
\hline
\end{tabular}

Fonte: (Vieira, 2015)

Ao se destacar o problema da água, infere-se os empreendimentos de hospedagem como indicadores de pressão, pois na alta temporada a um consumo muito maior de água devido o aumento da demanda. De modo que, o indicador de estado, seria a perfuração de poços artesianos para atender a necessidade por água em Barra Grande, podendo comprometer o volume subterrâneo dessa. Nesse caso, o indicador de resposta, seria a fiscalização por parte do Poder Público ou órgão competente, fato não comprovado durante a pesquisa de campo.

Quanto ao problema esgoto, o indicador de pressão seria o aumento da geração de efluentes na alta temporada, fato comprovado, com a falta de leitos na alta temporada. Considera-se a diminuição da qualidade da água, como estado. Por exemplo, com as inferências dos hoteleiros, que encontraram coliformes nas amostras de águas coletadas. Nesse caso, o indicador de resposta, seria também a fiscalização por parte do Poder Público ou órgão competente, fato não comprovado durante a pesquisa de campo.

No referente aos resíduos sólidos, a pressão seria o aumento da produção de lixo na alta temporada e depósito desse em local inapropriado. Tendo como indicador de estado, o lixão de Barra Grande, que impacta diretamente o meio ambiente, no caso os manguezais. Quanto ao indicador de resposta, não se percebeu iniciativas da gestão em minimizar ou acabar com o problema.

Com essa análise, pode-se ter uma visão integrada do desenvolvimento turístico local, pois os indicadores utilizados trouxeram um recorte dos problemas consequentes não só do turismo. Mas da ineficácia da gestão local em não resolver questões básicas, sobretudo, para população local, parte mais prejudicada de todo esse contexto social.

\section{CONCLUSÕES}

O planejamento do turismo e das políticas que o direcionam, considerando o viés da sustentabilidade é uma alternativa constantemente apresentada em estudos de destinos nacionais com características semelhantes à Barra Grande. Porém, não se percebeu nessas pesquisas, propostas de metodologias baseadas em indicadores objetivos e confiáveis, que qualificassem efetivamente os impactos negativos ao meio ambiente, e consequentemente, levantassem informações significativas para elaboração de medidas capazes de minimizar impactos. 
Foi feita uma reflexão teórica acerca das políticas públicas, sua relação com a sustentabilidade ambiental e o uso de indicadores como parâmetros para elaboração destas. Pode-se dizer que o Estado tem papel fundamental na formulação e direcionamento das políticas setoriais de turismo, pois o Brasil alcançou considerável crescimento e organização dessa atividade com a institucionalização das políticas, que orientaram e disponibilizaram mecanismos para que os municípios estimulassem a atividade turística em seus territórios.

No caso de Barra Grande, estas políticas poderiam estimular a adoção de medidas ambientais efetivas pelos empreendimentos turísticos, que apresentam problemas com a eliminação dos dejetos e destino dos resíduos sólidos, o que favoreceria a gestão ambiental nessas organizações. Poderiam ser criados prêmios de gestão ambiental municipal, a exemplo do Selo de Sustentabilidade do SEBRAE/PI, ou serem concedidos incentivos fiscais, não devendo funcionar como uma forma de isenção de responsabilidade do Poder Público.

Quanto ao conteúdo da política analisado se deu com a finalidade de verificar a efetividade das ações de conservação e preservação do ambiente natural para o desenvolvimento turístico local, assim destaca-se que ações voltadas para a manutenção do ecossistema local acontecem, mas não contemplam tudo o que é estabelecido nos documentos elaborados, um exemplo disso é a falta de monitoramento da gestão ambiental nos meios de hospedagem. Com base nas ações apresentadas para Barra Grande e na pesquisa de campo que levantou aspectos de 18 empreendimentos, pode-se dizer que a preocupação ambiental depende da visão que cada proprietário tem a respeito do seu empreendimento, não tendo sido observado o envolvimento em ações coletivas como a implantação de coleta seletiva ou outro programa com objetivo de reduzir os resíduos produzidos.

Espera-se que os dados levantados possam contribuir na condução do planejamento e gestão das políticas de turismo e meio ambiente, além de construir parâmetros para subsidiar discussões e novas abordagens de pesquisa, que contemplem a viabilidade e adesão de modelos de turismo sustentável, como o ecoturismo. Destaca-se, que no próprio Plano de Manejo da APA do Delta do Parnaíba, o ecoturismo é considerado uma das atividades específicas a ser desempenhadas na conservação do ecossistema.

\section{REFERÊNCIAS}

Almeida, J. R. D. (2010). Gestão ambiental para o desenvolvimento sustentável. Thex.

Becker, B. K. (2001). Políticas e planejamento do turismo no Brasil. Caderno Virtual de Turismo, 1(1), 1-7.

Beni, M. C. (2006). Política e planejamento de turismo no Brasil. São Paulo: Aleph.

Bobbio, N., Mateucci, N., \& Pasquino, G. (1998). Diccionario de política, vol. I. México, Siglo XXI.

CMMAD, C. M. S. M. A., \& Desenvolvimento, E. (1988). Nosso futuro comum. Fundação Getúlio Vargas. Rio.

De Oliveira, J. A. P. (2013). Empresas na sociedade: sustentabilidade e responsabilidade social. 
De Faria, C. A. P. (2003). Idéias, conhecimento e políticas públicas: um inventário sucinto das principais vertentes analíticas recentes. Asociação Nacional de Pós-Graduação e Pesquisa em Ciências Sociais.

De Souza, C. A. (2013). Resort-Uma Análise da Discussão Conceitual e Histórica. Revista Hospitalidade, (2).

Donaire, D. (1995). Gestäo ambiental na empresa. Atlas.

Guimarães, R. P. (2001). A ética da sustentabilidade e a formulação de políticas de desenvolvimento. $O$ desafio da sustentabilidade. São Paulo: Fundação Perseu Abramo, 43-71.

GuimaRães, R. P., \& Feichas, S. A. Q. (2009). Desafios na construção de indicadores de sustentabilidade. Ambiente \& Sociedade, 12(2), 307-323.

Gonçalves, C. W. P. (1989). Os (des) caminhos do meio ambiente. Editora contexto.

Instituto Brasileiro de Geografia e Estatística (IBGE). Indicadores do IBGE - Pesquisa Mensal de Serviços: Brasil (Janeiro de 2015). Disponível em:

<ftp://ftp.ibge.gov.br/Comercio_e_Servicos/Pesquisa_Mensal_de_Servicos/Fasciculo_Indicadores_IBGE/p ms_201501caderno.pdf>. Acesso em: 21 mar. 2015.

Instituto Brasileiro de Geografia e Estatística (IBGE). Indicadores do IBGE - Pesquisa Mensal de Serviços: Brasil (Janeiro de 2015). Disponível em:

<ftp://ftp.ibge.gov.br/Comercio_e_Servicos/Pesquisa_Mensal_de_Servicos/Fasciculo_Indicadores_IBGE/p ms_201501caderno.pdf>. Acesso em: 21 mar. 2015.

Lopes, B., AmaraL, J. N., \& Caldas, R. W. (2008). Políticas Públicas: conceitos e práticas. Belo Horizonte: SEBRAE.

Macêdo, E. M., \& Ramos, R. G. (2013). O desenvolvimento do turismo em Barra Grande, Piauí (Brasil) e seu significado para a comunidade local.RITUR-Revista Iberoamericana de Turismo, 2(2), 89-107.

Meadows, D. H., Meadows, D. L., Randers, J., \& Behrens, W. W. (1972). The limits to growth. New York, 102.

Merico, L. F. K. (2001). Políticas Públicas para a sustentabilidade. Viana G, Silva M, Diniz N. O desafio da sustentabilidade: um debate socioambiental no Brasil. São Paulo: Editora Fundação Perseu Abramo, 251262.

Ministério do Turismo. Plano Nacional de Turismo 2013-2016 - “O turismo fazendo muito mais pelo Brasil". Brasília, 2013.

Ministério do Turismo. Turismo já representa 3,7\% do PIB. Out. 2012. Disponívelem:<http://www.turismo.gov.br/turismo/noticias/todas_noticias/20121010-2.html>. Acesso em: 2 Dez. 2014.

Organização Mundial de Turismo. OMT. Guia de desenvolvimento do turismo sustentável. Tradução Sandra Netz. Porto Alegre: Bookman, 2003. 
Organización Mundial del Turismo. OMT. Lo que todo gestor turístico debe saber: guía practico para el desarrollo y uso de indicadores de turismo sostenible. Madrid: OMT, 1997.

Swarbrooke, J. (2000). Turismo sustentável: conceitos e impacto ambiental.São Paulo: Aleph, 1.

Tayra, F., \& Ribeiro, H. (2006). Modelos de indicadores de sustentabilidade: síntese e avaliação crítica das principais experiências. Saúde e Sociedade,15(1), 84-95.

Trentin, F., \& Sansolo, D. G. (2006). Políticas públicas de turismo e indicadores de sustentabilidade ambiental: um estudo sobre Bonito-MS.Turismo-Visão e Ação, 8(1), 61-74.

Artigo recebido em: 06/08/2015. Artigo aprovado em: 03/12/2015. 